\title{
Just Doing It: the role of experiential learning and integrated curricula in architectural education
}

\author{
Lara Mackintosh, Curtin University, Australia
}

\begin{abstract}
Transformative learning has been identified as contributing to the success of education programs in engendering sustainable behaviour in the built environment. In professional degree programs such as architecture, what impact does the nature of the learning experience of students have on the opportunities for transformation? Transformative learning is supported by opportunities for critical reflection, increased self-awareness of learning, and visible demonstration of progress. The teaching of design in architecture includes many of these elements, but in other core teaching, such as culture and science, the learning experience tends to be more transmissive in its nature. This paper will explore examples of alternative methods of architectural education which include experiential learning - learning by doing as a way of developing understanding and making meaning - and integrated curriculum - using the information and skills learnt in one subject to explore ideas in another. By investigating the learning experiences as a system, and considering the different contexts in which learning can take place, an ethno-methodological approach will be used to identify and document key elements of the transformative learning experience. The findings from this investigation will inform the development of a pedagogical framework for environmental education, such as architecture.
\end{abstract}

Key Word: Architecture, Education, Transformation, Learning, Pedagogy

\section{Background}

$\mathrm{E}$ xperiential learning, supported by an integrated curriculum, contributes to the transformative learning experience and supports shifts in point of view of the learner. Mezirow defines transformative learning as "the social process of construing and appropriating a new or revised interpretation of the meaning of one's experience as a guide to action." (Mezirow 1994, 222-3). Critical to this is the requirement for a new or revised interpretation of experience, implying change in behaviour and understanding. When skills and knowledge gained through formal traditional forms of transmissive instruction - lectures, research, and collection of information - are able to be applied in real time to a project-based task, the impact of the learning and development of metacognitive skills is strengthened and supports a shift in values and change in behaviour beyond the classroom.

In order to understand how architectural education can support transformation in the student, the learning experience is considered part of a dynamic system of learning. This system comprises the contexts in which the learning takes place, the actors participating in the experience, and the interaction and consequent action taking place within the system, all contribute to ongoing change within the system. The contexts of learning are the different situations in which learning takes place. Four main contexts have been identified. The built environment, the man made physical context of learning includes formal settings such as school and other learning institutions, as well as the everyday built environments in which informal learning takes place. The natural environment is more typically an informal learning context, though some formal learning programs use the natural environment as the setting for formal learning activities. The social context of learning is considered to be the people with whom the learning is experienced, and at its broadest level can involve entire communities. The educational context for learning incorporates the curriculum and content of the learning, as well as pedagogical approach of the learning experience.

While each of these contexts can be considered discrete, it is the relationships between these contexts, and the interactions that take place, that are seen as critical to a transformative learning experience. Walden notes that there are many aspects which influence the experience and behaviour of people as they interact with their environments (Walden 2009). Rather than a causal relationship between environment and behaviour, he recognises that "individual behaviour is not only determined by the social and physical environment, but the individual in turn changes reality by his or her behaviour" (Walden 2009, 3). This approach recognises the multiple changes that may occur through experience and is applied here when considering the learning experience as a complex system. It allows for an understanding of the relations, actions and outcomes of learning, namely behaviour, to be developed. This 'systems approach' of understanding change has been applied in sociology since Parsons first described social systems as complex, open and dynamic (Parsons 1965). Garfinkel, a student of Parsons, developed enthnomethodology as a means of understanding why behaviour occurs and to identify patterns and relationships within social behaviour (Garfinkel 1967). Developing this further, Francis and Hester posit that ethnomethodology focuses upon understanding the "methods by which members of society are able to observe and recognise what is happening around them, and thereby know what they should do to fit their actions together with the actions of others" (Francis and Hester 2004, p. 24). They recognise that making sense of experience is not something detached from action, but rather something that is made in action. Such action is seen here as part of the system of learning. This approach has been used here to 
begin to develop a way of understanding learning experiences; how this affects the way in which people behave and how this behaviour may be changed.

Focusing on architectural education this paper explores the opportunities for transformative learning as evidenced in two case studies - the Rural Studio, part of the architecture program at Auburn University, Alabama; and the architecture program at Victoria University of Wellington in New Zealand. These two programs have been selected as both are well respected, long standing programs, with documented success in teaching. These studies are part of an ongoing research project investigating the role of environmental education, and more specifically architectural education, in supporting long term sustainable behaviour.

\section{Teaching and architectural education}

In architectural education, it is typically in design studio where students are required to complete project based tasks. This is supported by other study areas such as technology, and history and theory. Accreditation for architecture courses in Australasia requires students to demonstrate skills and understanding which are aligned with those required of professionals (Architects Accreditation Council of Australia 2008). This requires creative problem solving, effective visual written and oral communication and demonstration of application of understanding in all key areas.

A study into Australasian Schools of Architecture identified that recent changes in architectural education has led to a fragmentation of the curriculum (Ostwald 2008). This fragmentation has resulted in each of the study areas being seen as a discrete area of focus, and an implied connection to other study areas. While this study focussed on the Australasian region, architectural education and curriculum has been internationalised, and that many of the issues reported in the Australasian survey are also applicable to other regions (Ostwald 2008). In response to this fragmentation, opportunities for teaching practices to reconnect across curricula are sought and this paper seeks to find evidence of this in the learning experiences and teaching practices observed in the case studies. This involves an understanding not only of the learning experience, but of the model of teaching practiced in each of these programs.

Winter et al describe pedagogy as a content model of teaching, where the transmission of information and skills, predetermined by the teacher, is focussed on filling perceived deficits in students' knowledge and comprehension (Winter et al. 2008). Developed over centuries from its origins in monastic schools in the Middle Ages, pedagogy, a teaching rather than learning theory, is common in current education practice. In architecture schools this is often the way in which the study areas supporting design are taught where content is typically delivered in lectures, and tutorials are offered to support development and critical thinking, as students explore and discuss issues related to set topics. Assessment tasks are often focussed on understanding of content and theory, and skills learnt.

An alternative to the pedagogical theory, andragogy, views learning as a transaction between the teacher and the learner, in which the needs of the learners are addressed as teachers facilitate the process of content acquisition by providing leads to other content resources (Knowles 1980). It focuses on the learning process, and allows the learner to become independent and self-directed. This is achieved by the teacher facilitating experiences through which the topic, or what is being learnt, is able to be directly related to learners own life experiences (McAuliffe et al. 2008). Critical to this is the immediacy of the application of theory to project (Knowles 1980). This learning theory is considered effective in an adult learning environment, such as higher education, as it requires the learner's awareness of their own learning needs, and an ability to actively plan and engage in the learning process (McAuliffe et al. 2008).

\section{Observing architectural education in practice}

An ethno-methodological approach has been taken to understand the nature of learning within the programs, focusing on the relationship between the actors and the contexts of learning. A number of evidence collection methods were used to record the interactions and actions that took place, including interviews, observations and field notes, audio recordings and photographs. Analysis of this evidence has commenced in order to define different models of learning experiences within architectural education and to identify the extent to which transformation of the learner can be measured. One component of the learning experience has been focussed on within each of the programs studied, as the whole programs are complex and the learning experiences within them diverse. It is acknowledged that the evidence collected is not wholly representative, as there are many ways in which learning within and about environments can take place. The intent here is to use this evidence as a way of illustrating possibilities, and to inform the development of a framework.

\section{Rural Studio}

Rural Studio has a long history of 'learning by doing'. Since 1993 architecture students from Auburn University have been coming to Newbern, Alabama, to live, learn and make architecture alongside and for the community. 
Founder Sam Mockbee started Rural Studio with the belief that through the action of solving real problems and providing a built solution that is useful, the outcomes of the learning experience are meaningful for all involved and transformative.

Third year students come to Newbern for a semester only and while doing so they live full time on the Rural Studio Farm in accommodation built by previous Rural Studio students. Fifth year students, those in their final year of formal study, spend an entire year developing, designing and constructing a small architectural project. The students live in a nearby town in rented accommodation. For both cohorts, the experience is an immersive one, where students are encouraged to engage and participate in community activities as well as their own learning activities.

The teaching practices observed at Rural Studio reflect an approach to teaching closer to andragogy than pedagogy. Projects are moderately complex in types of material, methods of construction and brief, and there is a high level of technical difficulty in both skills and understanding. To support this experts are brought in for a series of intensive workshops as and when required. These workshops typically focus on the non-design study areas, such as technology. Table 1 below shows some the activities that took place in one of these workshops where the fifth year students designed a complex structural system, calculated its strength, and tested models to determine performance and efficiency.

Table 1: Rural Studio: fifth year students testing and applying structural strategies to architectural projects.

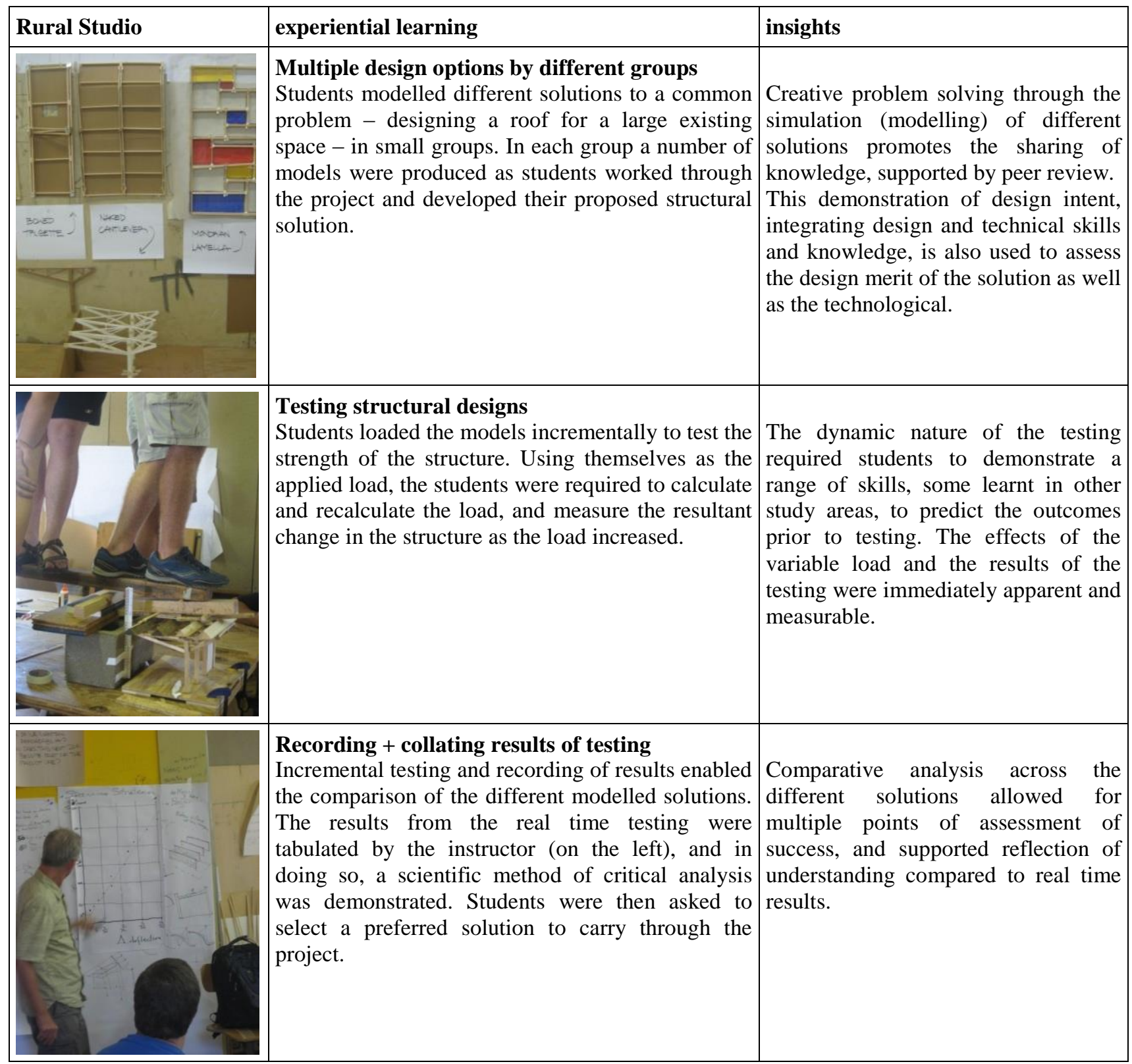




\begin{tabular}{|l|l|l|}
\hline Rural Studio & experiential learning & insights \\
\hline 4 & $\begin{array}{l}\text { Applied to design project } \\
\text { Here, students demonstrate their understanding of } \\
\text { the process and how it may affect design decisions } \\
\text { made by using multiple modes of visual } \\
\text { communication (written, 2D and 3D drawings as } \\
\text { well as photos and diagrams) }\end{array}$ & $\begin{array}{l}\text { Thessons learnt in the structural } \\
\text { workshop were applied to their } \\
\text { design. It reflects the iterative } \\
\text { approach as similar tasks were } \\
\text { previously undertaken in third year, } \\
\text { such as the process of knowing and } \\
\text { the simulated testing of a theory. }\end{array}$ \\
\hline
\end{tabular}

Source: authors own photos, 2012.

\section{Victoria University of Wellington}

A more pedagogical approach is taken in general in the architectural program at Victoria University in that the timetable is more traditional and comprised of weekly lectures, studios and tutorials. However, some of the outcomes of the program have been exceptional, in particular the Firstlight project for the 2011 Solar Decathlon. Of interest in this case study were the learning experiences that lead to this ground breaking project. As this project had been completed prior to the study, the focus of observations was the staff within the program, many of whom are involved in teaching across year groups, across curriculum and in some cases across courses. Table 2 below shows examples of the teaching practice of one particular staff member who was closely linked to the Firstlight project. Classes in Design and Technology units were documented as these relate to the specific focus of the sustainable design/build project.

Table 2: Victoria University of Wellington: teaching activities of one staff member.

\begin{tabular}{|l|l|l|}
\hline Victoria University & integrated curricula & $\begin{array}{l}\text { Second year Design Studio Tutorial } \\
\text { The students presented their concepts } \\
\text { and design ideas for a light rail train } \\
\text { station in Wellington. }\end{array}$ \\
\hline $\begin{array}{l}\text { Activities include practices such as } \\
\text { peer and staff involvement in project } \\
\text { review and one on one discussions }\end{array}$ & $\begin{array}{l}\text { Third year Technology Lecture } \\
\text { The focus of the lecture was a built } \\
\text { project in Wellington used to } \\
\text { demonstrate the application of theories } \\
\text { in practice. The lecturer was a part of } \\
\text { the architectural team for this project }\end{array}$ & $\begin{array}{l}\text { The lecturer used a subjective narrative } \\
\text { style, relating personal experiences on } \\
\text { local projects. This contrasted to use a } \\
\text { more abstract narrative when lecturing } \\
\text { in design about visual communication } \\
\text { and presentation techniques. }\end{array}$ \\
\hline
\end{tabular}




\begin{tabular}{|c|c|c|}
\hline Victoria University & integrated curricula & insights \\
\hline & $\begin{array}{l}\text { Fourth year Design Studio Tutorial } \\
\text { The developed designs presented by } \\
\text { the students involved the refurbishment } \\
\text { of nearby buildings which had suffered } \\
\text { earthquake damage. The students were } \\
\text { focussed on preserving historic and } \\
\text { cultural significance as well as future- } \\
\text { proofing the buildings structurally. }\end{array}$ & $\begin{array}{l}\text { Students referred to learning from } \\
\text { technology units as they presented their } \\
\text { design projects and vice versa, } \\
\text { referring to their designs to illustrate } \\
\text { the application technological theory. } \\
\text { These design and technology tutorials } \\
\text { were held in the same studios. }\end{array}$ \\
\hline
\end{tabular}

Source: authors own photos, 2012.

\section{Evidence of integrated curriculum and experiential learning}

There was evidence within both the programs observed of elements of both experiential learning and an integrated curriculum. In Rural Studio a more andragogical model than pedagogical was observed, especially in the fifth year where learning involved a method of investigation and testing that relied on previously developed skills as part of the approach to project based learning. It was clear that these skills, first observed in the third year activities, were further developed in the final year, and that the staff expected students to use these skills as part of their design process. In addition to activities such as the structural exercise undertaken (table 1), during design 'crit' sessions, where students work in progress is displayed and reviewed by their peers and staff, the questions focussed on the decision making process rather than the outcome of the process. Students were encouraged to make rigorous and well informed decisions, based on their own investigations. Having staff on hand to support the process, and by providing specialists at times where the information had become critical to the project, the students were able to determine the direction of the project and the focus of their investigations. By applying skills and knowledge from across their course to a real-life project students are also developing skills in self-directed problem solving, both as a team and independently.

At Victoria University of Wellington the learning experience was more pedagogically focussed and demonstrates an integrated curriculum. Traditional lectures and tutorials were used to deliver content relevant the design projects that students were working on at the time and staff directly linked the activities in one unit to those in another. This requires knowledge and awareness across the curriculum, and the coordination of assessment and content. As shown in table 2, the teaching activities of some members of staff ranged across year groups and study areas. This vertical integration through the course, along with cross curriculum teaching activities of the staff allows for the coordination and the relevancy of the content from one unit to another for the duration of the five year program, supporting the effectiveness of a teaching focussed pedagogical learning experience.

Observing and documenting the learning experiences within the two case studies has provided evidence of methods of teaching. In addition, analysis of this evidence has highlighted three key aspects of the learning experience that influence the opportunities for transformation.

\section{Relevancy of content to immediate task}

Supporting both the pedagogical and andragogical approach is the relevancy of the immediate learning experience to other recent experiences. Where the content is relevant to one or more of the assessment tasks across the curriculum, or new skills and knowledge are required to be demonstrated in more than one study area, the learning experiences in each of the discrete classes is more likely to be meaningful.

At Victoria University of Wellington, this was clearly evident where content delivered in a technology unit was not seen as interesting and had limited student engagement. The focus of the unit was the skills and knowledge required by a graduate, and the examples used illustrated theory and principles unrelated to their design project. For students with more than one year remaining in their studies, it is difficult to connect this to their other immediate learning experiences However, content delivered in different, non-design unit, delivered in a similar lecture style, held in the same lecture theatre, elicited a different response. Students later reported to their design tutor that they found it inspiring. As the content of the lecture was directly related to their immediate tasks in design, and was something which they could explore in their own work it was able to be applied immediately.

At Rural Studio, the schedules of the classes and their content are planned so that expert knowledge is provided intensively at critical moments. With the third years, their semester starts with an exploration of the local area as part of a history class, which serves not only to help them develop an understanding of the area, but also provides a source of information directly related to their design project. In fifth year, the students 
participated in a structure workshop demonstrated in table 2, at the time when key decisions about design intent, materials are being made. In these classes, students are developing knowledge through content acquisition, but are also developing skills through application in multiple ways. Exploring the local area through drawings develops communication and analytical skills that a valuable in design. Using models to test a structural strategy requires skill not only in understanding the science of architecture, but also the importance of accuracy in model making, and the use of modelling to consider design beyond the aesthetic.

\section{New and familiar experiences and context}

The newness or familiarity of experience can impact on the effectives of the learning. New experiences are seen as important when considering transformative learning experiences, as this support a change in values or a way of understanding the world. Familiar experience supports the learners, and serve to reinforce and strength existing interactions. This newness and familiarity of experience, is related to the contexts of learning for all actors within the learning system, staff and students alike.

At Rural Studio, both the physical and natural contexts are new, as many of the students are not familiar with the area. They are experiencing the rural landscape and towns for the first time, and the situation is very different from the Auburn University campus, where the students undertake the majority of their architectural studies. However the immediate social context is very familiar as students have completed at least two years study together and although the staff are new to them, the small size of the program and allocation of staff to specific year groups supports the rapid development of a close relationship between staff and students. There are also many components of the educational context that would feel familiar to students. The units are similar in names, format and learning outcomes to those conducted at the main university campus. The students are practised in the multiple modes of communication required, visual, spoken and written. In addition, staff were familiar with the students work across the units and had awareness outside of their main teaching focus, so that when specialist workshops were held, they were able to explicitly state the connections possible. Many have taught at Rural Studio for a number of years, and the familiarity with previous students work was also crucial, as this work was relied upon as part of the development of a much larger, long term project. For the fifth years, many of the things that seemed new in third year would now be familiar, though changes may have occurred during their absence. However, the expectations, of both the staff and the community, seem to increase for the fifth years, and the level of ability and critical thought is higher. It could be argued, therefore, that the educational context was in part new, and that associated with this, new skills and modes of interaction were required.

At Victoria University of Wellington, as many of the students live close to the campus, the immediate built and natural contexts would seem very familiar. As many students were designing projects in the immediate area, this familiarity supports engagement in their learning experiences, as they experience site and landscape as part of their everyday activities. The social context was familiar to the students as, similar to Rural Studio, they had spent close to two years studying together. In addition, there was evidence in the content and delivery of information that showed that the educational context was both new and familiar. A staff member, when lecturing on technology, used examples more likely to be familiar to students to explain his point, as they were local or high profile. Alternatively, another staff member used unfamiliar international examples, which students were less likely to have visited or been familiar with. In both cases however, there were aspects to the examples used that were new and familiar. They provided an opportunity to understand a familiar problem in a new way or to develop new understandings about a familiar problem. In this way, the educational context could be considered to be new.

\section{Learning individually and with peers}

At both Rural Studio and Victoria University of Wellington, larger cohorts are broken down into smaller groups. At Rural Studio, small groups of four, or sometimes pairs, are required to work together to explore a specific issue related to design. Each group is given a different focus and at the conclusion of the exercise, they present their findings to the whole class. This was done for a number of tasks in a number of different units, each time with a different group. As the projects progressed, the students developed their own individual concepts, yet referred to the work done by themselves and others as part of their design process. This is supported by the ongoing documentation the students are required to prepare as part of their studies.

Activities at Victoria University of Wellington also involve peer review of assignments in a number of units, with formal feedback given, and peer discussion during informal design crits. Typically, the level of engagement observed was high. Students seemed generous with their information and feedback, particularly in fourth year, where skills related to this were more developed, and the nature of the design project was collaborative, as students were required to coordinate individual projects on adjacent sites.

\section{The role of integrated curriculum and experiential learning in transformative learning}


Both case studies, with their different approaches to teaching and learning, have within their programs ways of integrating curriculum that supports effective and engaging learning. The situating of design projects in real life at Victoria University of Wellington, and the physical testing and making of architectural solutions at Rural Studio demonstrate experiential learning through creative problem solving in different ways. Key elements of the observed learning experiences are regarded to be supportive of transformative learning when considered in relation to known theories of transformative learning.

\section{Supporting transformation through learning}

The definition of transformative learning by Mezirow stated earlier is supported by others. When discussing transformative learning in higher education, Atkin identifies four 'pillars of education' that are experienced throughout life - learning to know, learning to do, learning to live together (social), learning to be (personal) (Atkin 1999, p.11). As learning within each of these takes place, beliefs are challenged, and through this challenge, the potential for change, for transformation, is created. In this way learning occurs as a result of dynamic interaction and growth, as this involves constructing and reconstructing our meanings and values, our beliefs, of and about the world. When considering learning as part of a system, this change is what supports the dynamic nature of the system, as new meaning is made through experiences and action, which result in perspective transformation, which in turn influences further experiences and action within the system. Perspective transformation is seen here as an important driver for behaviour change, an outcome of transformative learning.

Taylor, investigating perspective transformation in models of educational practice, identifies four key elements seen as critical - disturbing dilemma, or a challenging of assumptions and beliefs; opportunities for critical reflection that support a reassessment of orientation; the context, both social and physical surrounds of the learning experience; and relationships, as an 'other way of knowing (Taylor 1997, 45-49). These elements can be found in the system of learning experience, when considering the ways in which the actors and the contexts interact, and could be considered in the development of architectural education programs. Learning in new contexts challenges the students and their view of the world, while being supported by familiar contexts encourages and reinforces the existing behaviour, skills and knowledge required to support incremental change. If contexts are all new or too familiar, this may inhibit transformation as the experience are either overwhelming in the first instance, or not challenging in the second. Applying skills and knowledge acquired through different modes of interaction and communication immediately, within all the educational contexts, provides an opportunity for knowledge of a topic learnt transmissively to become associated with knowledge that is learnt through experienced. In doing so, multiple ways of knowing and understanding can be developed, supporting new interpretations and meanings. Learning with and from peers, and being able to find a place within the social context of learning, supports an understanding of self through reflection which is strengthened through connections with others.

While the programs studied contain these critical elements of a transformative learning experience, the study has also been used to investigate ways in which actual transformation of behaviour occurs. This is seen here as the first step of developing a way of identifying change in behaviour as a result of learning. However, it was also possible to recognise transformation in the behaviour observed which could be considered a outcome of the learning experiences.

\section{Recognising transformation}

Taylor also notes that while it was difficult to define the outcomes of perspective transformation in the literature reviewed, Mezirow recognises that an increase in self confidence in new roles and relationships is an outcome of perspective transformation (Taylor 1997, 49) and is considered an observable and identifiable change in behaviour. However, some studies reviewed by Taylor found this too narrow a definition. Psychological changes, evidenced in the understanding of oneself; convictional changes seen in a revision of a belief system; behavioural changes in lifestyle; increase in personal power; increased compassion for others; and a new connectedness with others were all given as examples of outcomes of change brought about by perspective transformation (Taylor 1997, 49-50).

This approach has been adopted when considering the two case studies, as the observed behaviour of staff, final year students and recent graduates of both programs displayed evidence of three of these identifiable changes: an exhibited confidence in new situations or at levels higher than expected; commitment and compassion for others; and high levels of connectedness with others.

At Rural Studio, many of the final year students expressed and exhibited an obvious compassion for others. This was evident in the fact that a few students had elected to stay on beyond graduation, so they could complete the project they had started as part of their studies. For some, this was contrary to the common financial and social expectations to start their professional career. A connectedness with others was also evident, particularly in the staff. Some of the staff are alumni of the program, and had stayed on or elected to return. When 
interviewed they recognised that the relationship with the students and the local community was a primary reason for this. The fifth years exhibited a confidence that was not evident in the third years. While some of this confidence comes with the increase in age and maturity, it seemed to extend beyond that seen in students of other architectural programs. The fifth years negotiated the cost and supply of materials for the planned build, met with community members regarding design intent and progress, and consulted with local artists and practitioners. In doing so they demonstrated skills and abilities more commonly expected of experienced professionals (Architects Accreditation Council of Australia 2008).

As a part of the process of completing their studies at Victoria University of Wellington, a number of students (now graduates) initiated, lead and completed a the Firstlight project, as part of the 2011 Solar Decathlon International Competition. The four members of this leadership team exhibit many of the signs of perspective transformation. They first met when working together as part of a masters (fourth and fifth year) design project. They completed their masters thesis on the same project, each looking at a separate element of the project. Similar to the fifth year at Rural Studio, the tasks completed by the students, which included project and team management, research project definition and completion, negotiation with the university regarding funding and support in kind. All task requiring a confidence beyond that normally expected. The four team members have also established an architectural firm with one of the staff members who supported the Firstlight Project. This is seen as not only related to confidence, but as evidence of ongoing connectedness with others. This is also evident in many of the practitioners who teach and tutor on a part time basis, as Victoria University of Wellington has strong professional and industry involvement. The environmental commitment of the Firstlight project has been continued by the team who state that "technology and sustainability should not only be affordable, they should also meld around how we live as" as part of their vision (First Light Studio 2013). This is seen as evidence of an ongoing commitment to long term goal of sustainable practice and lifestyle, which was initiated by the learning experience.

\section{Conclusion}

Traditional forms of architectural learning are engaging and involve many aspects of experiential learning and integrated curriculum based around creative problem solving activities. The case studies presented here offer evidence of programs that have embedded integrated curricula and experiential learning and that are considered transformative. The different modes of teaching, pedagogical and andragogical, are seen as supporting this. However when considering the learning experience as a dynamic system, in which the contexts, the actors and the interactions taking place are seen as contributing to change in the system, key aspects of these programs have been identified as supporting transformative learning. The relevancy of the content across the course, and the opportunity to immediately apply skills and knowledge to new situations supports the development of new ways of knowing and understanding. Ensuring that the contexts of the learning experience are both new and familiar supports a change in belief and behaviour that is supported by existing skills and knowledge. Learning with others, acquiring and applying new knowledge while developing independence and self-direction supports a sense of self within a broader social context are considered key elements of transformative learning experiences. In the case studies presented different modes of teaching practice, responding to different contextual situations within the learning system, and supported by for experiential learning, real or simulated, and an integrated curriculum replicates real-world experiences and transformation can be seen in the behaviour of in students, graduates and staff alike. The learning experiences within both of the programs are considered to be transformative, as the experiences have supported and contributed to significant change in behaviours and values in both the students and the staff involved.

However it is important to recognise that an understanding of the particulars of the contexts of the learning experience, and the nature of the actors and interactions within a system of learning, must be understood in order to develop and implement change. The case studies presented here are offered as examples of teaching practice and outcomes, and have served to support future research. The discussion presented here will be used to support ongoing curriculum and program development, and development of academics in their teaching and learning practice within architectural education.

\section{References}

Architects Accreditation Council of Australia. 2008. The National Competancy Standards in Architecture. Canberra: Architects Accreditation Council of Australia.

Atkin, J. 1999. Values for a Learning Community: Learning to Know. In Victorian Principals' Conference. Melbourne.

First Light Studio. Our Vision 2013 [cited 3 May 2013. Available from http://firstlightstudio.co.nz/about/ourvision/. 
Francis, D, and S. Hester. 2004. An Invitation to Ethnomethodology - Language, Society and Social Interaction. London: Sage Publications Ltd.

Garfinkel, H. 1967. Studies in Ethnomethodology. Los Angeles, CA: Prentice-Hall.

Knowles, M. S. 1980. The modern practice of adult education. New York: Cambridge Press.

McAuliffe, M., D. Hargreaves, A. Winter, and G. Chadwick. 2008. Does pedagogy still rule? In 19th Annual Conference of Australiasian Association for Engineer Education. Yeppoon: QUT Digital Repository.

Mezirow, J. 1994. "Understanding transformational theory." Adult Education Quarterly no. 44:222-32.

Ostwald, M., Williams, A. 2008. Understanding Architectural Education in Australasia Volume 1: An Analysis of Architecture Schools, Programs, Academics and Students. Sydney: Australian Learning and Teaching Council.

Parsons, T. 1965. "An Outline of the Social System." In Theories of Society: Foundations of Modern Sociological Theory, edited by T. Parsons, Shils, E., Naegele, K., Pitts, J. New York: The Free Press.

Taylor, E. W. 1997. "Building Upon the Theoretical Debate: A critical reveiw of the empirical studies of Mezirow's transformative learning theory." Adult Education Quarterly no. 48:34-59.

Walden, R. 2009. Schools for the future: design proposals from architectural psychology. Cambridge. Mass.: Hogrefe \& Huber.

Winter, A., McAuliffe M., D. Hargreaves, and G Chadwick. 2008. The Transition to Academagogy. In Philosophy of Education Society of Australiasia (PESA) Conference 2008. Brisbane, Queensland: QUT Digital Repository.

\section{ABOUT THE AUTHOR}

Lara Mackintosh: Lara Mackintosh has over 15 years' experience in the profession working in the residential, retail and educational sectors. Now, as an academic in Perth at Curtin University School of Built Environment, Lara has been developing her keen interest sustainability in architecture through her research and teaching practice. Her current research activities are associated with developing a holistic approach to architecture, in which the social, economic and environmental issues of sustainability in the built environment can be addressed both through practice and the education of architects. Lara is currently exploring this as a PhD candidate. The focus of her thesis is the development of a pedagogical framework for environmental education to support long term sustainable behaviour. 